\title{
Qualification of Underfills, Fluxes and Solder Resist for Flip Chip Applications
}

\author{
Aulis TUOMInEN, ${ }^{*}$ Ville LEHTINEN, and Eero RISTOLAINEN ${ }^{a}$
}

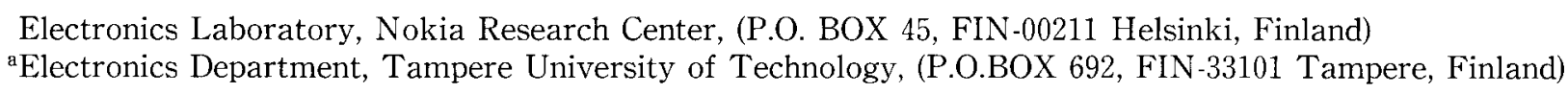

Received December 8, 1998 ; Accepted April 22, 1999

\begin{abstract}
The compatibility of flip chip fluxes, underfill epoxies and solder resists on printed circuit boards (PCB) was compared by using a single lap shear test. ${ }^{1-3,15)}$ The underfill adhesion to the plain solder resist was generally good, but in flip chip assembly, a flux for joining the connections of flip chips is used. Therefore, the PCB samples coated with different solder resists were fluxed and reflowed to simulate the real production environment. The underfill was applied on these residues and another piece of PCB, treated in same way was attached on it maintaining a consistent gap between two pieces. The underfill was cured according to each manufacturer's specification and a single lap shear test was carried out. The correlation of the variable results was verified by assembling a test flip chip using some of the tested materials and subjecting them into temperature cycling. The adhesion strength was verified by investigating underfill delamination by scanning acoustic microscopy (SAM).
\end{abstract}

Key Words : Underfill Adhesion, Flux, Solder Resist Com-Patibility, Flip Chip Reliability

\section{Introduction}

In flip chip attachment, the selection of the proper materials is more important than in the conventional joining method. When the soldered surfaces are minimal in size, the selection of the pad and bump material as well as the flux used are of vital importance. The wettability of the fluxes can be judged by using a wetting balance tester and the possibility of electrical leakage and electromigration by surface insulation resistance test (SIR) and visual inspection. Verification is usually done by using an assembly of daisy chained chips, which are monitored, while simulating a real-life environment by temperature cycling. ${ }^{4-6)}$ This is a rather standard method also in surface mount technology (SMT) qualification tests. In flip chip joining, the use of underfill for absorbing the mismatch caused by different CTE of substrate and chip, creates additional needs.

Usually, the underfill is applied underneath the chip after chip assembly, by using capillary action. The underfill must adhere well to substrate and to chip as well as to solder bumps to enable it to absorb the mismatch of CTEs. ${ }^{7,8)}$ Substrate thickness affects reliability ${ }^{9,10)}$ as does the gap, (stand-off, determined by the surface tension of solder), between chip and substrate. ${ }^{10-12)}$ The flux residues remaining on the substrate produce a very thin film and possible adhesion problems with underfill material. ${ }^{10,13)}$ Moreover, the solder resist used can also cause compatibility problems with underfill or with fluxes and possibly release absorbed solvents during reflow. ${ }^{10,14)}$ In some cases the underfill applied underneath the chip might not adhere to the surfaces at all. It is clear that, for good adhesion, the surfaces should come into intimate contact with the underfill material. The maximum work of adhesion, $W_{\mathrm{A}}$, is related to the three-phase surface and interfacial energies, $\gamma_{\mathrm{LV}}$ (liquid/vapour), $\gamma_{\mathrm{SL}}$ (solid/liquid) and $\gamma_{\mathrm{SV}}$ (solid/vapour) as shown in Fig. 1. The maximum $W_{\mathrm{A}}$ can be achieved, when the wetting angle,q, between the liquid adhesive, underfill, and the solid surface is zero. The work of adhesion is directly related to the surface tension of the liquid adhesive, $\gamma_{\mathrm{Lv}}$ (liquid/vapour), and the contact angle that the liquid makes with the solid. This can also be expressed by the well-known Young-Dupre Equation, Formula

$$
W_{\mathrm{A}}=\gamma_{\mathrm{LV}}(1+\cos \theta)
$$

Although theories concerning the adhesion between organic surfaces have been set forth, all phenomena involved are not yet well understood. Also, manufacturers are not willing to disclose the exact recipes of the materials. Thus, the best method to find out the adhesion strength is to make experimental tests. As the variety of materials available is myriad, it would be far too expensive and time consuming to test all combinations by using assembled test boards.

In the present study, underfill compatibility with different fluxes and solder resists applied to the sub-

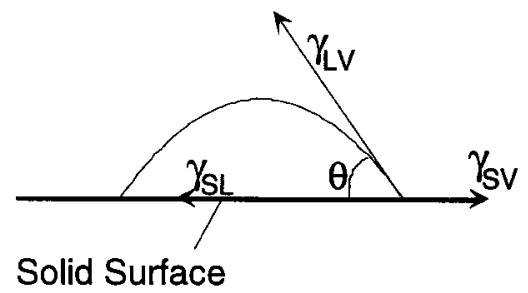

Fig. 1 A liquid drop of the adhesive on the solid. 
strates is evaluated. The PCB specimens were made of FR-4 laminate (Flame Retardant, grade 4). On the PCB specimens having different solder resists, qualified fluxes are spread and specimens are then reflowed to remove the volatile materials. These specimens are attached to each other by underfill maintaining a consistent gap between them. The adhesion strengths are then tested by the single lap shear test.

\section{Experimental}

For the adhesion single lap shear test, several pairs of the $1.6 \mathrm{~mm}$ thick FR 4 laminates (Fig. 2), were produced. The samples, ordered from different manufacturers, had a total of 4 kinds of solder resists on them. The size of the overlapping area on each specimen was $6.9 \mathrm{~cm}^{2}$. All specimens were cleaned in isopropyl alcohol (IPA) in an ultrasonic cleaner for 10 minutes prior to applying flux. After selection of the fluxes by wetting balance and SIR tests, five fluxes were selected for the test. The FR-4 specimens were fluxed by using a brush and reflowed in an ordinary surface mount device (SMD) reflow furnace with the temperature profile used in production. The purpose of this procedure was to simulate the real situation and remove the volatile materials from the surface of the test specimens. Underfill was applied then and two pieces of the specimens were attached together. Five kinds of underfill materials were selected for this test after some initial trials and study of the material specifications. All combinations were not tested due to the large number of possibilities. Some of the specimes were left without flux (NF), as a reference. The curing was done according to specifications of each underfill manufacturer. The gap between the two surfaces was specified to be $100 \mu \mathrm{m}$, though in real flip chip assembly, the stand-off is often less. After curing, the pull test was performed with a dedicated machine, MTS 858 Table Top. The machine is computer controlled and has a system for recording exact pulling force and speed. In order to get reliable results we repeated the test 3-5 times with

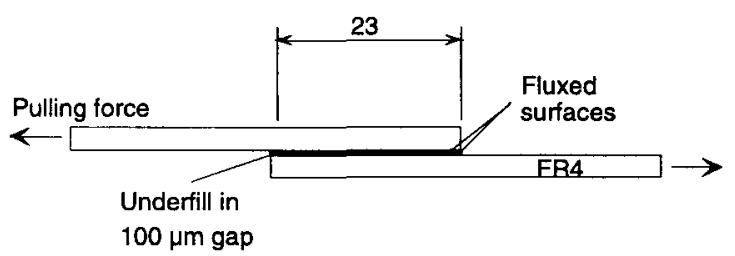

Fig. 2 The principle of the lap shear test. The width of specimens is $30 \mathrm{~mm}$. exactly similar combinations. The adhesion shear strength was calculated by dividing the pulling force by overlapping area. In Table 1 the preselected material combinations for the single lap shear test are shown. The material information of underfills, fluxes and solder resists are described in Tables 2-4.

The pulling speed of the machine was set to 0.05 $\mathrm{mm} / \mathrm{s}$. ISO 4587-1979 specifies that the average joint should be broken in a period of $65 \pm 20 \mathrm{s.}^{2)}$

The cured and cooled specimen was put between grippers of the pulling machine arms as shown in Fig. 3 and the upper gripper was raised under computer control until the joint was broken. The temperature in the test room was $25^{\circ} \mathrm{C}$. In Fig. 4 , the Force-Extension curves of underfill $c$ and solder resist 3 with flux $B$ and without flux are shown. The extension is mainly due to substrate elongation, not the joint itself. The point where the force-extension curve deviates from linearity is known as the proportional limit. At this point the strain is no longer recoverable and the sample cannot return to its original shape.15)

All the specimens were collected and the broken surfaces were visually examined to observe the failure mode. If the underfill shows cohesive fragmentation, or the substrate specimen breaks up, the adhesion is successful, but if the failure occurs in the interface of underfill and solder resists, it is an adhesive failure.

The shear strength to reliability correlation was verified by assembling the 71 input/output (I/O) flip chips on the test board from one vendor having solder resist 3 on them. The fluxes used in this test, were $A$ and $C$ and the underfills $a, c$ and $e$, respectively. The assembly was made by using Universal GSM-1 placement machine. The assembled boards were subjected

Table 1 Material combinations in the test.

\begin{tabular}{|c|c|c|c|c|c|}
\hline $\begin{array}{c}\text { Under } \\
\text { fill }\end{array}$ & $a$ & $b$ & $c$ & $d$ & $e$ \\
\hline Flux & \multicolumn{5}{|c|}{ Materials tested on solder resists types : } \\
\hline$A$ & 1,3 & 4 & $1,3,4$ & 1,2 & 3 \\
\hline$B$ & - & - & 1,3 & 1,2 & - \\
\hline$C$ & 1 & 4 & $1,3,4$ & - & - \\
\hline$D$ & - & - & 1 & - & - \\
\hline$E$ & 1 & 4 & 4 & - & - \\
\hline No Flux & 3 & 4 & $1,3,4$ & - & 3 \\
\hline
\end{tabular}

Table 2 Underfill properties.

\begin{tabular}{|c|c|l|l|c|}
\hline Underfill & Epoxy resin & Hardener & Filler & Catalyst \\
\hline$a$ & Cycloaliphatic epoxies & Anhydride & Fused silica & Imidazole \\
\hline$b$ & Bisphenol F type epoxy resin & Anhydride & Fused silica & Imidazole \\
\hline$c$ & Naphthalene type epoxy resin & Anhydride & Fused silica & Imidazole \\
\hline$d$ & Mono-, di and trifunctional epoxies & Anhydride & Fused silica & Amine \\
\hline$e$ & Cycloaliphatic epoxies & Anhydride & Fused silica & Imidazole \\
\hline
\end{tabular}


Table 3 Flux properties.

\begin{tabular}{|c|c|c|c|c|c|c|}
\hline Flux & Solid content & Halide content & Solvent & Activator & Resin type & Residue type \\
\hline$A$ & $60 \%$ & $<0.05 \%$ & Glycol ether & N/A & Denatured resin & Thermo plast \\
\hline$B$ & $70,30 \%$ & $0 \%$ & Aliphatic hydrocarbon & Carboxylic acid & Modified rosin & Thermo set \\
\hline$C$ & $65 \%$ & $0.0194 \%$ & Glycol derivatives & Carbonic acid, aliphatic carbon & Polymerised rosin & N/A \\
\hline$D$ & $2 \%$ & $0 \%$ & 2-propanol & Adipic acid & N/a & Thermo plast \\
\hline$E$ & $78 \%$ & $1.00 \%$ & Glycolether & Halides & Polymer resin & Thermo plast \\
\hline
\end{tabular}

Table 4 Solder resist properties.

\begin{tabular}{|c|c|c|c|c|c|c|}
\hline Solder Resist & Resin & Hardener & Filler & Pigment & Solvent & others \\
\hline 1 & Epoxy & Epoxy & Inorganic & $\mathrm{N} / \mathrm{A}$ & Volatile glycol ether & Photoinitiator \\
\hline 2 & Denatured epoxy & $\begin{array}{l}\text { Amine } \\
\text { com- } \\
\text { pound }\end{array}$ & $\begin{array}{l}\text { Barium sulfate, } \\
\text { talc, silica }\end{array}$ & $\begin{array}{l}\text { Phthalocya- } \\
\text { nine green }\end{array}$ & $\begin{array}{l}\text { Aromatic hydrocarbon, } \\
\text { carbitol acetate, dipropylene } \\
\text { glycol mono methyl ether }\end{array}$ & $\begin{array}{l}\text { Aromatic carbonyl } \\
\text { compound }\end{array}$ \\
\hline 3 & Denatured epoxy & $\begin{array}{l}\text { Dena- } \\
\text { tured } \\
\text { epoxy }\end{array}$ & Barium, silica & $\begin{array}{l}\text { Phthalocya- } \\
\text { nine green }\end{array}$ & $\begin{array}{l}\text { Glycol ether solvent, pe- } \\
\text { troleum naphtha }\end{array}$ & $\begin{array}{l}\text { Photo polymeriza- } \\
\text { tion initiator, addi- } \\
\text { tives }\end{array}$ \\
\hline 4 & $\begin{array}{l}\text { Modified epoxy } \\
\text { acrylate }\end{array}$ & $\begin{array}{l}\text { Epoxy } \\
\text { resin }\end{array}$ & Silica & $\begin{array}{l}\text { Phthalocya- } \\
\text { nine green }\end{array}$ & $\begin{array}{l}\text { Butyl glycol acetate } \\
\text { Dipropylene glycol methyl } \\
\text { ether, Butyl carbitol }\end{array}$ & $\begin{array}{l}\text { Photoiniators } \\
\text { Flow agents }\end{array}$ \\
\hline
\end{tabular}

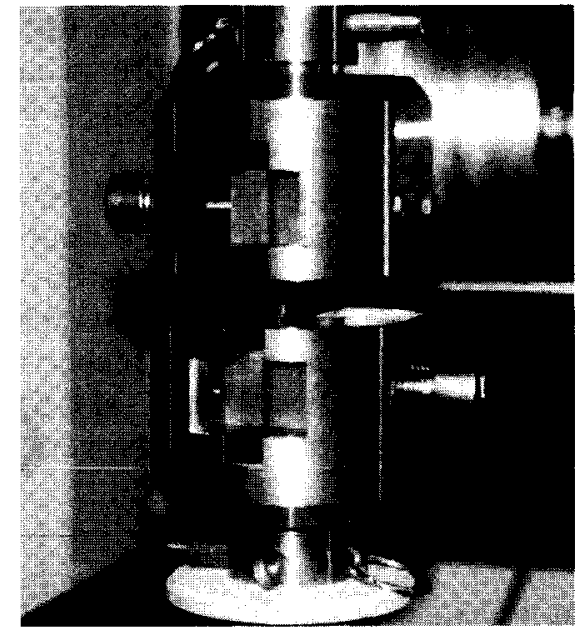

Fig. 3 Lap shear test specimen in the pulling machine's grippers.

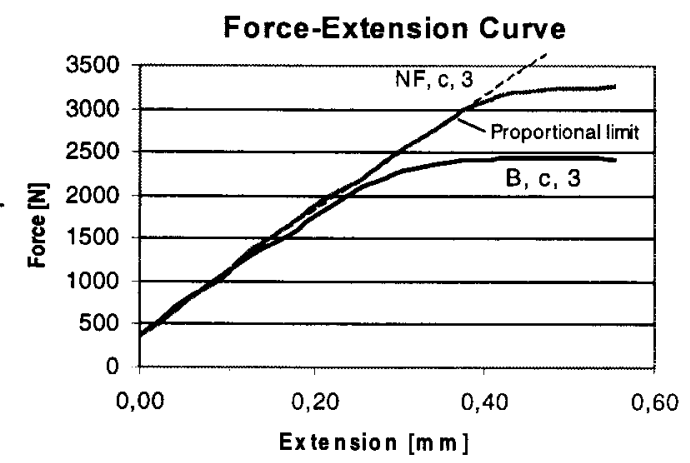

Fig. 4 Force-Extension curves of the specimens with the combinations of underfill $c$ and solder resist 3 , lower curve fluxed with flux $B$ and upper curve without flux.

to the liquid-to-liquid shock test (LLS) from $-55{ }^{\circ} \mathrm{C}$ to $+125^{\circ} \mathrm{C}$ for 1500 cycles. This test is severe and can be used for environmental stress screening (ESS). The analysis to detect delamination was made by using a scanning acoustic microscope (SAM).

\section{Results and Discussion}

The force achieved by the pulling machine was converted into MPa. The achieved results showed big differences with different material combinations. The results seemed to prove that the liquid types of fluxes leave fewer harmful residues on the substrate, thus allowing better adhesion to occur. The different types of residue have varying effects on adhesion. Moreover, the compatibility of the flux, not only with the underfill material, but also with the solder resist, has very great impact on the total functionality of the adhesion system. In Fig. 5, the single lap shear test results by each tested combination are shown in $\mathrm{MPa}$.

The results show that, as expected, flux residues impair the results and this must be taken into account when selecting materials for flip chip assembly. There is one exception, however. The adhesion of underfill $b$ to solder resist 4 is improved when fluxed with flux $C(7.4 \mathrm{MPa})$. This is also the best result of all combinations tested. Since the result is an average of 5 tests in this case, the result is significant. Flux $C$, underfill $c$ and solder resist 3 give one of the poorest results $(0.73 \mathrm{Mpa})$, though underfill $c$ and solder resist 3 without flux seem to work well (6.54 Mpa). This might be due to glycol residues in flux $C$. They react intensely with anhydrides in the epoxy leaving the epoxy hardening unfinished. On the other hand, flux $C$ contains amine acid, which works as an adhesion promoter. ${ }^{16)}$ Underfill $c$ works well with flux $A$ and solder resist $4(4.1 \mathrm{Mpa})$ as well as on solder resist 1 using flux $B(4.3 \mathrm{Mpa})$. Solder resist 4 is acrylate resin, thus being very good for adhesion. This is obviously the also reason for the very good result 


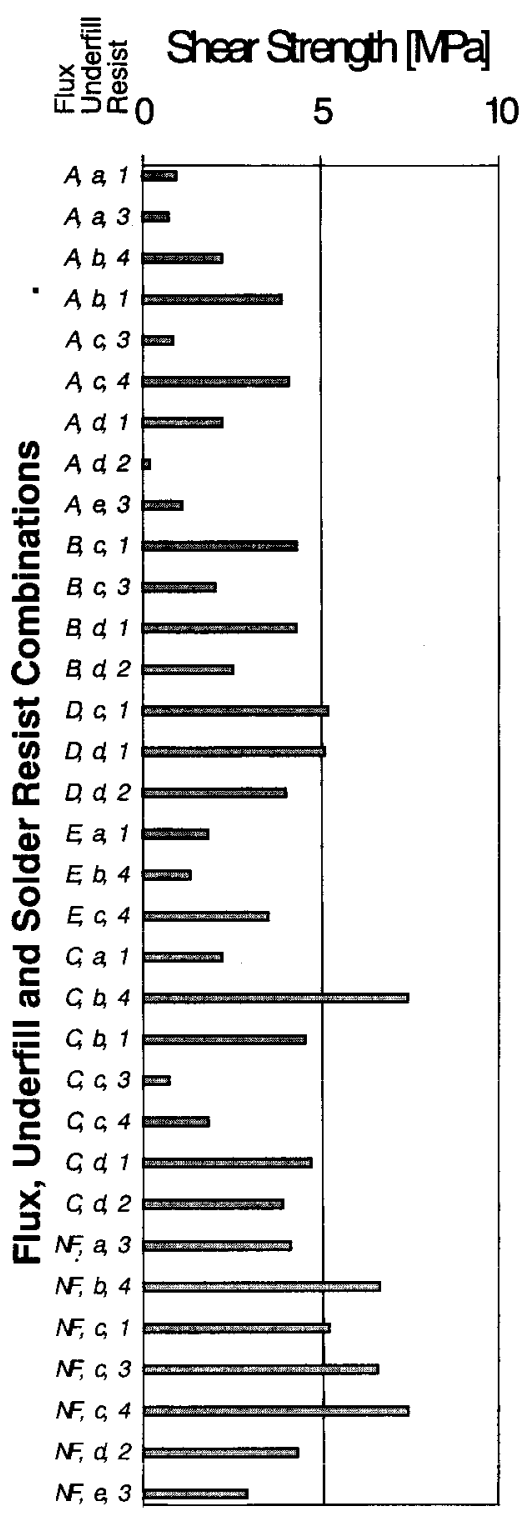

Fig. 5 The shear strength of underfills in single lap shear test with different flux and solder resist combinations.

with flux $C$ and underfill $b$. Solder resist 1 has good adhesion except for only a fair result with flux $A$ and underfill $a(0.94 \mathrm{Mpa})$. Poor adhesion is obtained with flux $A$ and underfill $a$ on solder resist $3(0.73 \mathrm{Mpa})$. The manufacturer of flux $A$ does not disclose many details of the materials used, but most probably $A$ with glycol ether solvent, leaves glycol residues reacting with the hardener which is anhydride. Also, the thermoplast types of residues seem to give poorer adhesion. Flux $A$ on solder resist 3 gave slightly better results with underfill $c(0.85 \mathrm{MPa})$, and with underfill $e$ (1.09 Mpa).

The material combinations selected for the assembly test were considerably poorer, when compared to the best shear strength results. They showed a very good correlation, however, to the achieved values in the lap shear test. The results of delamination were judged based on the SAM results as shown in Fig. 6 .

In Table 5, the liquid-to-liquid shock (LLS) test results after 1000 cycles and 1500 cycles are shown.
The shear strength of each combination is also includ ed.

It can be seen that, when the shear strength is over 1.0 $\mathrm{Mpa}$, the reliability is very good as no failures occurred after 1000 cycles. Under $0.8 \mathrm{MPa}$, the reliability is not acceptable. The best shear strength is 7.4 $\mathrm{MPa}$, thus well exceeding the reliability needs.

The lap shear test has a severe drawback due to stress concentration near to the end of the overlap, as shown in finite element analysis of the specimen, Fig. 7. This means that failure is caused by peak stress and in particular by peak tensile stress, rather than by the average shear stress across the joined area. This problem is stated also in ASTM, D 4896-95. ${ }^{17)}$ When dividing the achieved force by the overlapping area, the results cannot be considered as the true shear strength of the underfill, but can be used only in

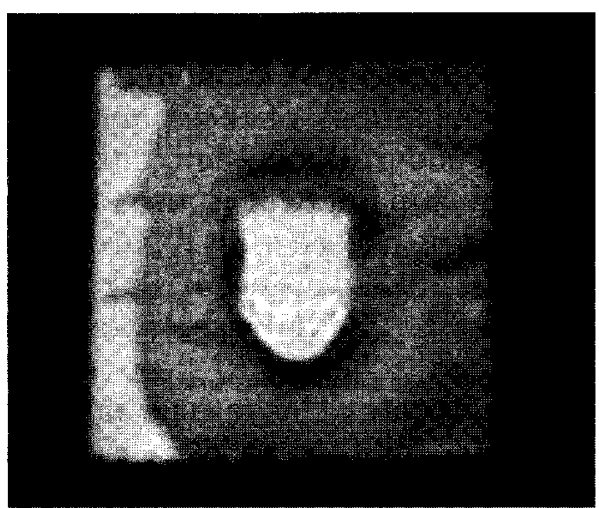

Fig. 6 SAM image of the delamination of underfill. The light section on the left side shows delamination of underfill. The light area in the center is caused by the fiducial marks underneath the chip on the substrate.

Table 5 Underfill delamination after LLS test.

\begin{tabular}{|c|c|c|c|c|}
\hline Flux & Underfill & $\begin{array}{c}\text { Lap } \\
\text { shear } \\
\text { strength } \\
{[\mathrm{Mpa}]}\end{array}$ & $\begin{array}{c}\text { Failures } \\
\text { after } 1000 \\
\text { cycles } \\
{[\%]}\end{array}$ & $\begin{array}{c}\text { Failures } \\
\text { after 1500 } \\
\text { cycles } \\
{[\%]}\end{array}$ \\
\hline$A$ & $a$ & 0.73 & 1.94 & 9.13 \\
\hline$A$ & $c$ & 0.85 & 0.08 & 2.00 \\
\hline$A$ & $e$ & 1.09 & 0.0 & 0.50 \\
\hline$C$ & $c$ & 0.73 & 1.67 & 17.58 \\
\hline
\end{tabular}

Lap Shear Test Variation

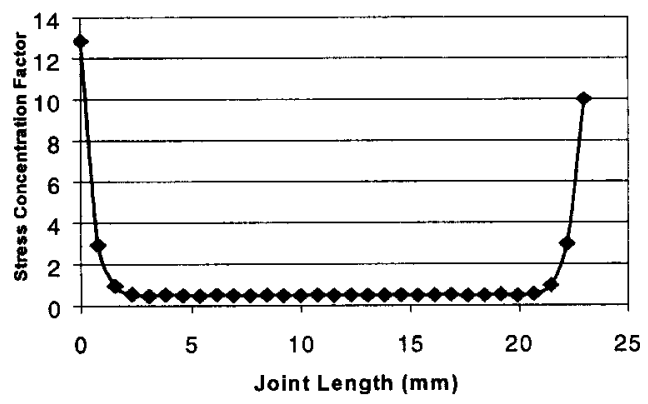

Fig. 7 The uneven stress distribution on the overlapping area of a single lap shear test specimen. 
comparing the respective shear strengths of the combinations. Studies have, however, been made to overcome this problem, at least with solder joint tests. Stiffer metal specimens are V-grooved close to the interfacial area, thus allowing a uniform and pure shear stress distribution to remain constant throughout the test. ${ }^{18)}$

In the visual checking no purely cohesive failure was found. When the shear strength was over 4.5 Mpa, the failure occurred in the substrate, with mainly the solder resist being stripped away; when under 4.5 Mpa, the failure mode was adhesive or adhesive and partly cohesive. It is clear, that the solder resist adhesion on the substrate must be sufficient.

\section{Conclusion}

The adhesion of 5 underfills on substrates coated with 4 different kinds of solder resist, fluxed and reflowed with 5 fluxes was evaluated. It was shown that proper combinations of these materials have a great impact on underfill adhesion, thus affecting the reliability of flip chip joints. It is also clear that these materials cannot be chosen with regard to their individual properties, like wetting of flux, but must be qualified together to find an acceptable combination, which has enough adhesion to keep the flip chips firmly on the substrate. This is especially important; when the cleaning of flux residues is omitted. The non-clean flux concept was created to omit the cleaning process, but a thin film of residues still remains on the substrate. This residue should preferably be of the thermosetting type self-adhering to the solder resist and without glycol ether solvent, thus creating a good base for proper underfill adhesion. The widest process window can be achieved by an acrylic type of solder resist. The LLS test of the assembled boards showed a explicit correlation between delamination failures and lap shear strength, thus proving acceptability of the test for preselection of flip chip materials.

\section{Acknowledgement}

The authors would like to thank Ms. Kati Ojala at Nokia Mobile Phones for preparing the samples used in the tests, Mr. Roope Nikander at the Helsinki University of Technology for performing the lap shear tests and Universal Instrument Corporation for making the verification assemblies.

\section{References}

1) ASTM, Designation: D 3164-92 a, Standard Test Method for Strength Properties of Adhesively Bonded Plastic Lap-Shear Sandwich Joints in Shear by Ten- sion Loading.

2) ISO 4587-1979 (E), International Standard, AdhesivesDetermination of tensile lap-shear strength of highstrength adhesive bonds.

3) M. R. Witty, R. L. Sellers, J. R. Rosson, G. G. Walker, M. P. Meehan, R. L. Vadas, and D. K, Ward, Flip Chip Assembly on Rigid Organic Laminates: A Production Ready Process for Automotive Electronics, International Conference and Exhibition, Multichip Modules and High Density Packaging, Denver, Colorado April 15-17, (1998).

4) A. Tuominen, V. Lehtinen, K. Kulojarvi, J. Kivilahti, the 35th IMAPS Nordic Annual Conference in Stock. holm, Sweden, 21-23 September, (1998),pp. T2-1-T2-6.

5) A. Tuominen, A. Perttula, IEMT/IMC Conference, Omiya, Japan, (1997), pp. 321-325.

6) J. Maattanen, A. Tuominen, P. Palm, the 35th IMAPS Nordic Annual Conference in Stockholm, Sweden, 21-24 September, (1998), pp. T4-1-T4-6.

7) D. Suryanarayana, T. Y. Wu, J., A., Varcoe, Encapsulants Used in Flip-Chip Packages, IEEE Transactions on Components, Hybrids, and Manufacturing Technology, 16, (8), December 1993.

8) G. Hill, Electronic Packaging \& Production, August 1993, pp. 46-49.

9) C. E. Park, B. J. Han, H. E. Bair, V. R Raju, Journal of Material Science Letters 16, pp. 1027-6029 (1997).

10) G. O'Malley, J. Giesler, S. Machuga, IEEE Transactions on Components, Packaging and Manufacturing Technology-Part B, 17, (3). August 1994, pp. 248-255.

11) A. Tuominen., A. Perttula, E. Ristolainen, Future Fab International, Issue 4, 1, 1997, Technology Publishing Ltd, pp. 349-351.

12) A. F. J. Baggerman, F. J. M. Caers, J. J. Wondergem, and A. G. Wagemans, IEEE Transactions on Components, Packaging, and Manufacturing Technology-Part $B, \mathbf{1 9}$, (4), November 1996.

13) J. Giesler, G. O'Malley, IEEE Transactions on Components, Packaging and Manufacturing Technology-Part $B, \mathbf{1 7}$, (3). August 1994, pp. 256-263.

14) J. Partridge and P. Viswanadham, Organic Carrier Requirements for Flip Chip Assemblies, Nepcon West '94, Anaheim, Feb.- March, 1994.

15) S. R. Hartshorn, Structural Adhesives, Chemistry and Technology, Plenum Press, New York, N.Y., pp.414415, 24-26 (1986).

16) A. Pizi, and K. L. Mittal, Handbook of adhesive technology, Marcel Dekker Inc., New York, N.Y., pp. 59-60 (1994).

17) ASTM, Designation: D 4896-95, Standard Guide for Use of Adhesive-Bonded Lap-Joint Specimen Test Results.

18) T. Reinikainen, M. Poech, M. Krumm, and J. Kivilahti, Trans. ASME Journal of Elecltronic Packaging., Vol. 20, March 1998, pp. 106-113. 